\title{
Formação da literatura nacional: balizas histórico-culturais
}

\author{
Maria Célia Leonel* \\ José Antonio Segatto**
}

\section{RESUMO}

Objetivamos rediscutir os marcos histórico-cronológicos e culturais da formação da literatura brasileira. Tais marcos foram delineados entre as décadas de 1830 e 1880 e sistematizados nos decênios seguintes, quando se estabeleceram suas balizas fundamentais, determinando-se um cânone de obras e autores de acordo com escolas ou tendências em uma sequência evolutiva. As fronteiras entre as escolas só começaram a ser objetadas a partir da década de 1960 com a publicação de estudos, especialmente o de Antonio Candido, Formação da literatura brasileira de 1959. Nesse livro, tomando como base a herança histórico-crítica precedente e incorporando muitos de seus elementos, o autor repensa os marcos históricoculturais do nascimento da literatura e propõe, como seus momentos decisivos, o Arcadismo, no século XVIII, e o Romantismo, no XIX, de acordo com o estabelecimento de um sistema literário. Seis décadas depois, apresentamos uma sugestão de redefinição dos limites históricos das tendências literárias nacionais, incorporando resultados de perspicazes pesquisas anteriores, sobretudo a de Antonio Candido.

Palavras-chave: História da literatura brasileira. Antonio Candido. Formação da literatura brasileira. Balizas histórico-culturais.

* Professora titular da Universidade Estadual Paulista Júlio de Mesquita Filho (UNESP). Mestre em Letras Literatura Brasileira pela Universidade de São Paulo e doutorado em Letras Literatura Brasileira.

** Professor titular da Universidade Estadual Paulista Júlio de Mesquita Filho (UNESP). Doutor em História Econômica pela Universidade de São Paulo (1993) e Atualmente é professor Titular da Universidade Estadual Paulista Júlio de Mesquita Filho. 


\title{
The Formation of Brazilian Literature: Historical and Social Bases
}

\begin{abstract}
It is aimed to rediscuss the historical-chronological and cultural marks of the Brazilian Literature formation. These marks were delineated between the 1830's and 1880's and were systematized in the following decades, when their fundamental bases were established, determining a canon of works and authors according to literary movements or tendencies in an evolutionary sequence. The boundaries between these movements started to be objected from the 1960's on, especially with the publication of Antonio Candido's Formação da literatura brasileira in 1959. In this book, on the basis of the previous historical-critical heritage, incorporating many of its elements, the author rethinks the historical and cultural marks concerned with the birth of Brazilian literature and proposes, as its decisive moments, the 18th century Arcadism and 19th century Romanticism according to the establishment of a literary system. Six decades later, we proposed a suggestion of redefining the historical limits of the Brazilian literary tendencies, incorporating results of previous perspicacious researches, mainly Antonio Candido's ones.
\end{abstract}

Keywords: Brazilian literary history. Antonio Candido. Formação da literatura brasileira. Historical and cultural bases. 
[...] a representação histórica da literatura [...] não é só meio auxiliar de estudo, mas também é parte da história. (SCHLEGEL, 2011, p. 507).

O objetivo deste artigo é rediscutir os marcos históricocronológicos e culturais da formação da literatura brasileira relativamente ao processo de constituição do Estado nacional. Tais marcos foram delineados entre as décadas de 1830 e 1880 e sistematizados nos decênios seguintes, quando se estabeleceram suas balizas fundamentais e foi determinado um cânone de autores e obras de acordo com escolas ou tendências, supondose uma sequência evolutiva.

A demarcação de tais movimentos tornou-se referência básica para as histórias de nossa literatura na primeira metade do século XX - tanto para aquelas que passaram a ser consideradas “oficiais" quanto para as que não se enquadravam nesse padrão. As fronteiras entre as escolas só começaram a ser objetadas a partir da década de 1960 com a publicação de estudos, fundamentalmente o de Antonio Candido, Formação da literatura brasileira de 1959. Nesse livro, tomando como base a herança histórico-crítica precedente e incorporando muitos de seus elementos, o autor reflete sobre os marcos histórico-culturais do nascimento da literatura e propõe, como seus momentos decisivos, o Arcadismo, no século XVIII, e o Romantismo, no século XIX, para o estabelecimento de um sistema literário.

Seis décadas depois, acreditamos ser possível aventar uma redefinição dos limites históricos das tendências literárias incorporando resultados de perspicazes pesquisas anteriores tendo em vista uma compreensão diversa da formação do Estado nacional no Brasil. Concomitantemente a uma nova consideração da instituição da literatura, propomos sua sistematização histórica 
no interstício temporal que vai da publicação da História da literatura brasileira de Sílvio Romero, em 1888, à edição inicial da Formação da literatura brasileira.

\section{Literatura, história e ideologia}

As histórias da literatura - como já exaustivamente constatado - começaram a ser elaboradas por intelectuais ligados ao Romantismo, sendo acopladas ao processo de organização dos Estados nacionais na Europa na passagem do século XIX para o XX. A esse propósito, lembra-nos Carpeaux (2011, p. 14): "[...] foi o romantismo que criou a 'história da literatura' conforme o critério cronológico, como nós o conhecemos, e foi o romantismo que criou a noção de 'história da literatura universal'.”.

Elemento inerente à fundamentação da identidade e da cultura nacional, a literatura ganhou atribuição medular na organização dos Estados-nação. Simultaneamente, as histórias da literatura foram criadas para autenticar e sistematizar a produção literária em um determinado cânone de autores e obras. Como escreve Moreira (2003, p. 9), "Cabia à história da literatura reunir o acervo artístico da nação, orientar as reflexões sobre a produção literária, do qual resultou seu papel social, como instrumento de aglutinação de uma determinada sociedade.".

Assim, no Brasil - como em outros países da América Latina recém-criados -, desde o rompimento do estatuto colonial e do encetamento da edificação do Estado nacional, surgiu a necessidade de se conceber tanto uma literatura como, paralelamente, uma história literária. Esta deveria ser capaz não só de assegurar a existência da literatura brasileira, como também 
de assinalar seus caracteres e especificidades. Dessa maneira, a partir da terceira década do século XIX, desencadeou-se um movimento de criação da literatura nacional e da historiografia para autenticá-la. Nas palavras de Nunes (1988, p. 205), “[...] começaria a surgir no Brasil concomitantemente à implantação do romantismo, a sua historiografia literária, à qual se deve, em estreita conexão com o aparecimento de uma historiografia nacional, aquele reconhecimento legitimador.".

À vista disso, no decurso de algumas décadas, foi sendo idealizada uma história literária e, em sintonia com o Romantismo, a construção do Estado-nação. Não havia ainda, no entanto, uma "[...] literatura brasileira, como corpus objeto de historicização, quando a história literária julgou oportuno inventar sua existência." (MOREIRA, 1995, p. 82).

Estudos de Ferdinand Denis (Resumo da história literária do Brasil, de 1826), Joaquim Norberto ("Bosquejo da história da poesia brasileira", de 1841, introdução à antologia Modulações poéticas), de Santiago Nunes Ribeiro ("Da nacionalidade da literatura brasileira" de 1843), de Ferdinand Wolf (O Brasil literário: história da literatura brasileira, de 1863), e ainda antologias - que, no que se refere ao estabelecimento de cânone, têm tanta importância quanto as histórias da literatura -, como a de Januário da Cunha Barbosa (Parnaso brasileiro, de 1829/1830), a já mencionada de Joaquim Norberto, a de Francisco Adolfo Varnhagen (Florilégio da poesia brasileira, de 1853) entre outras publicações, levaram à concepção de uma tradição histórico-literária com importante papel cultural e ideológico na construção nacional. Construto coletivo, essa operação envolveu muitos intelectuais e a ação decisiva do Estado durante algumas décadas. 
Essas primeiras tentativas de construção de uma história da literatura foram retomadas e reelaboradas nos últimos decênios do século XIX e no primeiro quartel do XX. Entre tais empreendimentos, devem-se destacar: História da literatura brasileira, de Ś́lvio Romero, de 1888; "Introdução à história da literatura brasileira”, de Araripe Júnior, de 1887; História da literatura brasileira, de José Veríssimo, de 1916, e Pequena história da literatura brasileira, de Ronald de Carvalho, de 1919.

Embasadas em formulações - em voga na época positivistas, evolucionistas, naturalistas de Auguste Comte, Herbert Spencer, Hippolyte Taine, Henry T. Buckle e outros, tais obras impregnavam-se, em geral, de noções de raça, meio, língua, cultura. Ademais, essas histórias compartilhavam determinados fundamentos relativos à literatura nacional, quais sejam: ela nasce já com a colonização no século XVI ou no XVII; apresenta caráter evolutivo entre as escolas, gêneros e estilos; é compreendida de forma elástica e extensiva: romance, poesia, teatro, folclore, crônica, história, economia, direito, jornalismo, ciências etc.

Não obstante tais componentes essenciais comuns, há, entre essas histórias da literatura, especificidades que devem ser explicitadas: a) a de Sílvio Romero, elaborada sob uma visão determinista, tem como fundamento a miscigenação e é expressão da raça e do povo; b) a interpretação de Araripe Júnior, também determinista, enfatiza, por sua vez, não a raça, mas o meio - deriva dela a noção de "obnubilação brasílica" (adaptação da cultura europeia aos trópicos), da qual emana o "estilo tropical" (BOSI, 1978, p. XVI); c) já Veríssimo tem como paradigma a Histoire de la littérature française, de 
1894, de Gustave Lanson, "[...] que concilia o historicismo com a crítica impressionista." (VENTURA, 1995, p. 49) - ou seja, "Literatura é arte literária [...] sinônimo de boas ou belas artes." (VERÍSSIMO, 1963, p. 12); d) a de Ronald de Carvalho - não obstante ter exercido considerável influência - é um desdobramento, sem grande originalidade, da publicação de Sílvio Romero.

Ainda que filiadas a teorias e ideologias, de certo modo, datadas ou mesmo extemporâneas, essas obras e seus autores passaram a ter grande autoridade, afirmando-se e conservandose como referência básica, exemplar, tanto no ensino da literatura no nível médio e nas universidades, como na constituição das histórias literárias e do cânone da literatura ao longo de todo o século XX. A despeito de todas elas, individualmente ou em conjunto, terem, posteriormente, ascendência respeitável, o trabalho de Sílvio Romero foi, sem dúvida, o mais expressivo ao expor de maneira sistemática:

[...] a epopéia da nacionalidade, fábula cujas origens míticas se situavam na gênese do mestiço e do cruzamento de culturas, matrizes da diferenciação progressiva do povo e da sociedade nacional, de acordo com os padrões darwinistas e evolucionistas. Estabeleceu o esquema da formação e da presença do "espírito" nacional, segundo o modelo épico da continuidade ininterrupta. (VENTURA, 1991, p. 166, grifo do autor).

Nos anos 1950-60, esses arquétipos histórico-literários começaram a ser postos em causa, repensados e superados. Pelo menos três obras significativas foram publicadas - uma em sua terceira edição - nesse momento: A literatura no Brasil, entre 1955 e 1959, organizada por Afrânio Coutinho, reunindo ensaios de críticos variados e mesmo discrepantes, inicialmente 
apresentada em quatro tomos; Formação da literatura brasileira: momentos decisivos, de Antonio Candido, em 1959, em dois compactos volumes; e História da literatura brasileira: fundamentos econômicos, de Nelson Werneck Sodré, que, embora tenha sido publicada inicialmente em 1938, apresenta nova versão ampliada em 1960.

A primeira obra, sob a direção de Afrânio Coutinho, apesar das diferenças entre os colaboradores, mantinha certa harmonia teórica e congruência analítica estabelecida pelo organizador e procurava deslocar o enfoque da nação para a arte literária, ou seja, para a "crítica intrínseca ou estético-literária". (COUTINHO, 1955a, p. 71). Para ele, a história da literatura deveria ser, necessariamente, a história da arte literária "[...] no seu desenvolvimento autônomo, nas suas várias formas, isto é, o estudo da literatura no tempo." (COUTINHO, 1955a, p. 71). Mas, como outros historiadores, considera que ela seria ordenada pela descrição do "[...] processo evolutivo como integração de estilos artísticos." (COUTINHO, 1955a, p. 42). Com esse entendimento, afirma que a história literária - que concebeu e dirigiu - obedeceu à "[...] evolução das formas estéticas no Brasil corporificadas nos seguintes estilos: Barroquismo, Neoclassicismo, Arcadismo, Romantismo, Realismo, Naturalismo, Parnasianismo, Simbolismo, Impressionismo, Modernismo." (COUTINHO, 1955a, p. 48). Isso quer dizer que, apesar das inovações, a coletânea mantém, em boa parte, a periodização evolutiva dos estilos literários desde o século XVII, quando a literatura teria sido formada com o Barroco. A obra, vale lembrar, retoma também a tese da obnubilação de Araripe Júnior. 
O livro de Nelson Werneck Sodré (1960), por sua vez, embora incorporando formulações de George Lukács, tem como parâmetro concepções do marxismo de George Plekánov, para quem os produtos culturais são conectados aos "fundamentos econômicos" - como se lê no subtítulo da obra - ou mesmo por eles determinados.

Assim sendo, a formação da literatura brasileira é considerada pela perspectiva do materialismo histórico, constituindo-se em consonância com a emergência do povo no processo da história. Nesse sentido, o autor afirma que somente no século XIX, com o Romantismo, é que surgiu um esboço de literatura nacional - restringida pela herança colonial e pela transplantação cultural - que só se realizaria, de fato, no início do século XX, em especial, depois de 1930. Diz o autor:

Só na medida em que as condições econômicas evoluem, refletindo-se na ordem social, pela definição das classes e pelo papel que elas representam, conduzindo à formação de uma estrutura nacional de produção, é que surgem as possibilidades do aparecimento de uma literatura nacional. (SODRÉ, 1960, p. 18-19).

Observe-se que, embora valorize obras de antecessores, especialmente de Veríssimo, procura superá-las, rompendo com explicações evolutivas e conceitos periodológicos de escolas e gêneros. A seu ver, "[...] a simples enumeração de escolas, discriminando nelas as exterioridades formais e mostrando sua sucessão no tempo, representa um processo descritivo sem nenhuma importância.” (SODRÉ, 1960, p. 22).

Das três publicações, a de maior ressonância históricoteórica e analítico-crítica é, sem dúvida, a de Antonio Candido. A partir da herança precedente - sobretudo de Sílvio Romero -incorporando e atualizando criticamente muitos de seus 
elementos, ele repensa não só os marcos históricos da formação da literatura como também seus fundamentos. Ao elaborar seu estudo, demarca os "momentos decisivos": o Arcadismo, no século XVIII (mais cosmopolita), e o Romantismo, no século XIX (orientado por peculiaridades locais). Entre um e outro, haveria um duplo movimento dialético - "de tendências universalistas e particularistas" (CANDIDO, 1971, v. 1, p. 23) - e de continuidade e ruptura, ambas as operações almejando criar a literatura brasileira e construir a nação. Assim, constituirse-ia um "sistema literário" - formado por produtores de literatura, público receptor, mecanismo transmissor (a língua e o estilo) - que conduziria ao estabelecimento de uma tradição como resultado do processo acumulativo de autores e obras. $\mathrm{O}$ sistema literário seria consolidado entre as décadas de 1830 e 1870 , e seu ponto de chegada seria a obra madura de Machado de Assis, consubstanciação do longo e progressivo movimento de construção da literatura brasileira.

Essas três obras seriam, de fato, as últimas a apresentar inovações quanto às balizas da formação da literatura brasileira. Muitas foram as histórias literárias publicadas posteriormente, das quais cabe destacar a mais conhecida que é a História concisa da literatura brasileira, de Alfredo Bosi, de 1970. Entre outras, tem-se a Presença da literatura brasileira: história e antologia, de Antonio Candido e José Aderaldo Castello de 1964; a coleção A literatura brasileira, com seis volumes elaborados por diferentes estudiosos acerca de cada escola literária publicada pela Cultrix na década de 1960; a História da literatura brasileira, de Massaud Moisés, da década de 1980; A literatura brasileira: origens e unidade, de José Aderaldo Castello, de 1999. Todavia, nenhuma delas traz novidade no que se refere à periodização e à interpretação da história literária. 
Contrariamente, preservam as demarcações históricas tradicionais e os parâmetros evolutivos de escolas e gêneros, estabelecidos, como foi dito, na passagem do século XIX para o XX. Não obstante o rigor analítico, a densidade teórico-crítica e a maior repercussão acadêmica da História concisa da literatura brasileira, de Alfredo Bosi, ela manteve - não importando se para fins didáticos ou não - paradigmas pretéritos.

Mesmo a Presença da literatura brasileira, que conta com a autoria de Antonio Candido e de José Aderaldo Castello, conserva a periodização convencional, contradizendo a Formação da literatura brasileira, do próprio Candido. Pode ser que, como no caso de Alfredo Bosi, o intuito pedagógico levou os autores a adotarem os marcos tradicionais.

No último quartel do século passado, houve algumas tentativas de rever ou de desconstruir as histórias literárias sem, no entanto, apresentarem contribuições significativas. Isso porque começava uma outra história em que histórias de literatura nacional perderam a função cultural e ideológica - em particular a da elaboração de identidades nacionais.

\section{Marcos históricos}

Quando foram elaboradas as histórias da nossa literatura, de Ferdinand Denis a Sílvio Romero e deste a Antonio Candido e outros, partiu-se sempre do pressuposto, dado como inquestionável, de que o Brasil preexistia à constituição do Estado nacional. A literatura brasileira, portanto, já era um fato presente, desde o início do século XVI com a carta de Caminha, ou os autos de Anchieta, ou o poemeto épico (Prosopopeia, de 1601) de Bento Teixeira. 
Afrânio Coutinho (1981, p. 37), seguindo as proposições de Araripe Júnior, afirma mesmo que a literatura surgiu "[...] no instante em que o primeiro homem europeu aqui pôs os pés, aqui se instalou.". Naquele momento, "[...] criou-se um homem novo, obnubilando [...] o homem antigo, o europeu [...]" (COUTINHO, 1981, p. 38), e, com ele, nasceu a literatura pátria. Teríamos, dessa forma e com tal explicação, a literatura brasileira antes, ainda, da existência do Brasil ou da nação brasileira.

Evidentemente, tais elaborações não surgiram de meras conjeturas ideológicas. Elas provêm de interpretações históricas, construídas nos anos 1840-50, sistematizadas por Carl F. Ph. von Martius e Francisco A. Varnhagen, que estabeleceram as referências político-ideológicas e institucionais da versão oficial da história do Brasil. Desde então, "[...] os usos do passado colonial foram afirmativos da unidade e identidade nacionais." (HANSEN, 2008, p. 26).

Delineada tal narrativa historiográfica, “[...] os autores e as obras coloniais funcionam teleologicamente como antecipações exemplares que anunciam a grandeza do tempo dos intérpretes." (HANSEN, 2008, p. 26-27). O propósito patriótico implicou a recorrência, pelos analistas, às obras coloniais, como “[...] exemplos do ideal pré-formado na sua ideologia que transforma autores coloniais em protonacionalistas." (HANSEN, 2008, p. 29).

Isso posto, entendemos ser possível e necessário pensar em uma redefinição dos limites históricos das tendências da literatura com base em premissas e fundamentos de uma compreensão diversa do processo de constituição do Estado nacional. Assim, supomos a possibilidade de sistematizar e sintetizar a história literária segundo uma periodização exposta nos termos a seguir. 
a) Literatura colonial portuguesa (séculos XVI-XVIII)

A montagem da colonização portuguesa na América como constatado por muitos historiadores - realizou-se por meio da ocupação do território para a produção de gêneros tropicais altamente lucrativos no mercado europeu (açúcar, tabaco etc.) e da exploração de metais preciosos (ouro, diamantes) em larga escala, baseada no trabalho compulsório do escravo negro africano. "Engajava-se, assim, a ocupação, povoamento e valorização de novas áreas, e sua integração nas linhas da economia europeia." (NOVAIS, 1986, p. 68), regulada pelo estatuto colonial ou pelo exclusivo comércio com a metrópole.

Encetado pelo Estado português, associado à grande empresa mercantil, o empreendimento colonizador, amplo e abrangente, envolveu grandes recursos e resultou na constituição de uma sociedade diferenciada da europeia no território ocupado, ou seja, em uma formação social escravista. "Prolongamento da metrópole" (NOVAIS, 1986, p. 68), a colonização portuguesa no novo mundo foi sendo estabelecida ao longo de três séculos. Instituída por capitanias e circunscrições coloniais cuja coesão era bastante precária, compôs um conjunto heterogêneo, sem nenhuma unidade cujas partes se comunicavam antes com a metrópole do que entre si. O que existia de fato eram colônias (Norte, Nordeste e Sudeste), sem nenhum interesse comum e qualquer noção identitária, a não ser localmente ou com a metrópole de além-mar proporcionados pela língua e pela religião.

Além disso, papel de relevo coube à Igreja católica, em especial à Companhia de Jesus, organização criada pela contrarreforma. Aparato do Estado português, à Igreja coube 
atribuição não só missionária, mas, sobretudo, cultural e ideológica, de estabelecimento de normas de sociabilidade, controle e dominação, e seu caráter hiperconservador impregnou todas as relações sociais e humanas. Ademais, em áreas em que a alfabetização era raridade, quase que monopólio dos clérigos, a pauperização intelectual era agravada pelas severas restrições da metrópole à circulação e à publicação de livros e outros impressos.

Nessas condições, não poderia haver literatura autóctone e menos ainda brasileira, pois o país não existia. O que se tinha, segundo Antonio Candido (1971), do século XVI a meados do XVIII, eram manifestações esparsas, rarefeitas, isoladas, sem organicidade, no mais das vezes de repercussão local, sem formar uma tradição.

Observe-se que alguns críticos dessa tese, com pretensões inovadoras, acusam Antonio Candido de ter "sequestrado o barroco", por ignorar Gregório de Matos - "um dos maiores poetas de nossa literatura" - e Vieira - afirmando ainda que a literatura brasileira "não teve infância, já nasceu adulta, formada" (CAMPOS, 1989, p. 12). Na realidade, esse entendimento histórico está embasado em concepções políticoideológicas da versão oficial da história brasileira, fundada por Varnhagen, segundo a qual o Brasil preexistia à constituição do Estado nacional - ele seria mesmo uma continuidade da colônia portuguesa na América e sua história teve início com a "Primeira Missa". A literatura brasileira, tal qual no modelo positivista/ evolucionista, teria sido criada nos séculos XVI ou XVII, antes, portanto, da existência do país.

Assim sendo, pode-se asseverar que as manifestações literárias (de cronistas, poetas, tribunos e outros), dispersas no 
tempo (quase três séculos) e no espaço (regiões ou localidades determinadas), não podem ser concebidas ou estudadas como sendo constituintes da literatura brasileira, a não ser por meio de construtos ideológicos.

b) Pré-história: passagem do século XVIII ao XIX

De meados do século XVIII às primeiras décadas do XIX, houve um surto cultural significativo em uma região delimitada da colônia, as Minas Gerais, especialmente em Vila Rica e localidades próximas, estendendo-se por franjas que alcançaram São Paulo e Rio de Janeiro. Impulsionada pela economia aurífera, contou-se com a urbanização crescente (1730-80) de núcleos mineradores, acompanhada pela implantação de equipamentos de infraestrutura, por paulatina aglomeração demográfica, pela necessidade de burocracia civil e militar e pela ampliação das atividades da Igreja. Com isso, no setecentos, nas localidades mineradoras ou a elas vinculadas, foram criadas condições propícias ao afloramento da literatura com Cláudio Manuel da Costa, Alvarenga Peixoto, Tomás Antônio Gonzaga, Santa Rita Durão, Basílio da Gama, entre outros, e de demais atividades artísticas, como a escultura e a arquitetura, a pintura e a música sacra.

Nesse período e nessa região, aparece, por conseguinte, "O esboço de uma literatura como fator cultural configurado, e não apenas como produção individual de pouca repercussão." (CANDIDO, 2004, p. 33). O mesmo crítico já havia observado que as academias e, particularmente, o Arcadismo, tiveram papel importante, dado que esse último "[...] plantou de vez a literatura do Ocidente no Brasil." (CANDIDO, 1971, v. 1, p. 17). 
Esse processo ganharia novo impulso nas primeiras décadas do século XIX, quando da transferência do Estado português para a colônia (1808-21), mais especificamente para o Rio de Janeiro. Tal fato, ao revogar normas do pacto colonial, propiciou a criação de algumas premissas básicas para a fundação do Estado nacional e para a criação de uma literatura própria. "Imprensa, periódicos, escolas superiores, debate intelectual, grandes obras públicas, contato livre com o mundo [...]" caracterizaram a "Época das Luzes, acarretando algumas consequências importantes para o desenvolvimento da cultura intelectual e artística, da literatura em particular." (CANDIDO, 1971, v. 1, p. 227). Presenciouse o surgimento dos "[...] primeiros públicos consumidores regulares de arte e literatura; a definição social do intelectual; a aquisição, por parte dele, de hábitos e características mentais que o marcariam até nossos dias [década de cinquenta do século XX].” (CANDIDO, 1971, v. 1, p. 227).

Assim, pode-se dizer que esse período distingue-se do anterior, mesmo o território continuando na situação de colônia, por estabelecer condições para que, no momento posterior - de organização do Estado -, fosse possível o desencadeamento da criação da literatura brasileira. Tal ocorrência, no entanto, deve ser tipificada como pré-história, pois diz respeito à transição da condição de colônia para a de Estado nacional. Ademais, havia ainda outros elementos limitadores: o movimento cultural das Minas era ainda muito circunscrito a uma determinada região que, após a decadência do ciclo do ouro, experimentou uma contínua e irreversível involução. Assim, não havendo ainda país, nação e identidade nacional, não poderia haver literatura brasileira. 
c) Criação da literatura nacional: $1830-40 / 1870$

A constituição do Estado no Brasil foi um processo longo e descontínuo. Fundado em 1822, a partir da unidade imposta de cima, agregando circunscrições coloniais com poucos elementos de unicidade e identidade, ele continuou inconcluso por muito tempo. Sua formação requeria a criação de elementos fundamentais para a construção da nação, como povo, instituições e símbolos. Para tanto, havia a necessidade de gerar determinados quesitos de identidade e unidade nacional: sociedade civil e política, direitos de cidadania, exército e polícia, justiça, códigos, mercado interno, moeda, sistema fiscal e tributário, história, geografia, cultura, mitos, heróis, santos, hino, bandeira e, especialmente, literatura. De acordo com a compreensão aqui veiculada, a formação da literatura não pode ser dissociada da organização do Estado nacional, pois é um dos seus componentes basilares, acompanhando pari passu a sua constituição.

Assim, no processo de organização do Estado, uma elite de intelectuais, amparada pelo governo imperial e sob seu manto, elaborou uma política cultural objetivando a criação da cultura brasileira. Nela, a posição central coube à literatura em gestação nos anos de 1830-40/70, efetivada no movimento romântico, iniciada, conforme marcos tradicionais, em Paris, por meio da revista Niterói, em 1836, sob a liderança de Gonçalves de Magalhães. Tendo como referencial as proposituras de Ferdinand Denis em seu opúsculo Resumo da história literária do Brasil, de 1826, Magalhães propunha que a nossa literatura deveria diferenciar-se da portuguesa e superar a equivalência da língua pela temática local (americana) e pela natureza (tropical). 
Ademais, deveria ser estabelecida uma tradição, com elementos e aspectos precursores "[...] que pudessem vir a configurar uma tradição literária nacional brasileira." (ROUANET, 1991, p. 232, grifo do autor). Seu esboço tomava obras do século XVIII em que tais características eram encontradas como O Uraguai, de 1769, de Basílio da Gama, e Caramuru, de 1781, de Santa Rita Durão. A tradição ali encetada deveria ser retomada e ter prosseguimento pelo movimento romântico que valorizaria a representação da realidade nacional. É clara a ideia de imbricação íntima entre o movimento romântico e a construção da nação, ou seja, a literatura seria um instrumento fundamental no processo de organização do Estado-nação.

Seus princípios fundamentais, segundo Antonio Candido (1971, v. 1, p. 329-30), poderiam ser sistematizados da seguinte forma:

1) O Brasil precisaria ter uma literatura independente;

2) esta literatura recebe suas características do meio, das raças e dos costumes próprios do país; 3) os índios são os brasileiros mais lídimos, devendo-se investigar as suas características poéticas e tomá-las como tema; 4) além do índio, são critérios de identificação nacional a descrição da natureza e dos costumes; 5) a religião não é característica nacional, mas elemento indispensável da nossa literatura; 6) é preciso reconhecer a existência de uma literatura brasileira no passado e determinar quais os escritores que anunciaram as correntes atuais.

Os intelectuais românticos, tributários do nacionalismo, criaram as bases do que seria a literatura brasileira. Empenhados na "construção da nação", assumiram mesmo um "sentimento de missão" que os levava a "[...] considerar a atividade literária como parte do esforço de construção de um país livre.” (CANDIDO, 1971, v. 1, p. 26). 
Desse modo, a literatura de tendência romântica produziu obras que foram ao encontro da necessidade de geração de símbolos e imaginário, as quais contribuíram para a elaboração da identidade e da consciência nacional. É o que, de fato, ocorreu com José de Alencar em $O$ Guarani, em 1857, e Iracema, em 1865, e com Gonçalves Dias, em Os timbiras, em 1857, que procuraram estabelecer os mitos de origem, exercendo papel importante na concepção de uma identidade.

Concomitantemente ao indianismo, surge o romance urbano de Joaquim Manuel de Macedo, A Moreninha, de 1844; de Manuel Antonio de Almeida, Memórias de um sargento de milícias, de 1854, entre outros, e a poesia de Castro Alves, Casimiro de Abreu, Álvares de Azevedo, Fagundes Varela e outros mais. Temse também outra vertente denominada regionalista com Bernardo Guimarães e A escrava Isaura, de 1875; Alfredo d'Escragnolle Taunay e Inocência, de 1872; Franklin Távora e O Cabeleira, de 1876, e outros. Tal vertente tinha mesmo a intenção de "[...] substituir o indianismo, como aspecto formal e insistente na intenção de transfundir um sentido nacional à ficção romântica." (SODRÉ, 1960, p. 298). O Brasil genuíno seria o do sertão que conservaria "em estado natural os traços nacionais", atribuindose "[...] ao sertanejo, ao homem do interior, àquele que trabalha na terra, o dom de exprimir o Brasil [...]" (SODRÉ, 1960, p. 299).

Afrânio Coutinho (1955b, p. 149) afirma que o regionalismo se constitui de um "conjunto que arma o todo nacional", ou seja, que a soma de obras formaria uma espécie de mosaico literário, representando as especificidades locais - a unidade na diversidade. É, portanto, um construto político-ideológico imbuído de concepções variadas: localismo, provincianismo, nacionalismo. 
Antonio Candido (1971, v. 2, p. 117-118) entende que, nos anos 1870 , o sistema literário estaria plenamente configurado, a formação da literatura brasileira concluída e seu ponto de chegada seria Machado de Assis, que:

[...] se embebeu meticulosamente da obra dos precedentes. A sua linha evolutiva mostra o escritor altamente consciente, que compreendeu o que havia de certo, de definitivo, na orientação de Macedo para a descrição dos costumes, no realismo sadio e colorido de Manuel Antônio, na vocação analítica de José de Alencar. Ele pressupõe a existência de predecessores, e esta é uma das razões de sua grandeza [...] aplicou o seu gênio em assimilar, aprofundar, fecundar o legado positivo das experiências anteriores [...] Assim, se Swift, Pascal, Shopenhauer, Sterne, a Bíblia ou outras fontes que sejam, podem esclarecer sua visão do homem e a sua técnica, só a consciência de sua integração na continuidade da ficção romântica esclarece a natureza de seu romance.

À vista disso, o crítico julga que a obra machadiana, ao realizar de modo cabal a dialética do local e do universal em um processo mais amplo de constituição de uma tradição cultural e intelectual em que se destacou a literatura -, atesta a consubstanciação do largo e progressivo movimento histórico de constituição do "sistema literário", iniciado no século XVIII com o Arcadismo e que foi se adensando no século seguinte. É nessa perspectiva, segundo ele, que devem ser entendidos a forma e o conteúdo dos romances de Machado de Assis: um lento curso de formação do sistema literário criou uma tradição e os precedentes do grande escritor.

d) Configuração plena da literatura brasileira: 1880-1956

A formação da literatura brasileira, a nosso ver, entretanto, só alcançaria configuração plena em um período razoavelmente 
longo de mais de sete décadas, do último quartel do século XIX a meados do XX. Nesse largo intervalo, o Brasil passou por profundas transformações: de país agrário-escravocrata para sociedade urbano-industrial, de império para república. Naturalmente, tais modificações não se deram por completo nem mesmo nas regiões mais desenvolvidas. Como se sabe, ao contrário disso, permaneceram - e permanecem - relações sociais fortemente desiguais, mazelas de todo tipo, procedimentos e costumes de momentos anteriores - ainda que com outras roupagens, como o poder político-econômico dos latifundiários, entre outras persistências, como se pode constatar na melhor representação dessa continuidade nas décadas iniciais do século XX em Grande sertão: veredas.

De todo modo, no plano cultural, as mudanças mencionadas permitiram o afloramento de uma inteligência significativa, a ampliação da educação em vários níveis - ainda que de acesso limitado -, a instalação de equipamentos culturais e de formação, públicos e privados: jornais e revistas, teatros e cinemas, editoras e livrarias, rádios e televisões, universidades e centros de pesquisa etc.

Esse complexo de fenômenos tanto socioeconômicos quanto culturais teve intenso reflexo na produção literária nacional. No romance e na poesia, na dramaturgia e em outros gêneros, surgiram muitas obras e autores de grande valor, permitindo mesmo a emergência de uma literatura de amplitude universal, de que temos vários exemplos expressivos e mesmo extraordinários na prosa de Machado de Assis, Mario de Andrade, Graciliano Ramos, Guimarães Rosa e outros. Na poesia, contamos com Manuel Bandeira, Carlos Drummond de Andrade, João Cabral de Melo Neto entre outros.

Sobre o período de realização integral da nossa literatura, já havíamos avançado a hipótese que consideramos plausível: 
[...] a literatura brasileira, que começa a ser criada nos anos 1830/1870 com o Romantismo, ganha configuração plena entre a publicação do primeiro e do último grande romance brasileiro: Memórias póstumas de Brás Cubas, de Machado de Assis, em 1881, e Grande serão: veredas, de Guimarães Rosa, em 1956. Paralelamente a isso, a sistematização crítica, autenticada e normatizada do que seria a literatura brasileira, poderia ser demarcada no interstício histórico que vai da publicação da História da literatura brasileira, de Sílvio Romero, de 1888, à edição da Formação da literatura brasileira, em 1959. (LEONEL; SEGATTO, 2014, p. 186).

A insistente reposição, no século XX, de questões apresentadas pelo Romantismo no oitocentos foi bastante ativa no Modernismo. Nesse momento, houve a retomada - em outros termos e algumas vezes com maior realce - de temas e questões veiculadas pelo movimento romântico: a dicotomia nacionalismo/cosmopolitismo, as raízes culturais, as diferenças de linguagem em relação a Portugal etc. Do mesmo modo que Mario de Andrade, em 1942, Antonio Candido (1976, p. 112) reiterou tais analogias ao constatar a existência de dois momentos cruciais na literatura brasileira que alteraram cursos e revigoraram a intelectualidade: "[...] o Romantismo, no século XIX (1836-70) e o ainda chamado Modernismo (1922-45). Ambos representam fases culminantes de particularismo literário na dialética do local e do cosmopolita; ambos se inspiram, não obstante, no exemplo europeu.".

A política cultural do governo Vargas, nos anos 1930-45, teve também como centro a retomada do projeto de conclusão da nação. Novamente, temas e problemas foram reatualizados e repostos, salientando-se a condição inconclusa do Estado nacional de forma geral e da história da literatura em particular. Nesse contexto, a política cultural do Estado procurou mesmo 
apropriar-se do Modernismo e até cooptar alguns de seus representantes como Mario de Andrade e outros de menor significação como Cassiano Ricardo e Menotti del Picchia.

A historiadora Mônica P. Velloso (apud CARVALHO, 1999, p. 260) registrou que, na política cultural estadonovista, a literatura deveria refletir a realidade brasileira na sua autenticidade, devendo ser o "espelho da nação". Dessa maneira, sua missão seria a de contribuir, como instrumento cultural, para a constituição do Estado.

Posteriormente, nas décadas de 1950-60, a cultura e a literatura voltaram a ser utilizadas não só pelo Estado, mas também por movimentos oriundos da sociedade civil como instrumentos para a construção da nacionalidade. Porém, nesse momento, a literatura e sua história estavam na fase de configuração ampla. No período subsequente, nos anos de 1980 e seguintes, principalmente com o processo de globalização, as literaturas nacionais foram perdendo, paulatinamente, o sentido de existir ou o propósito para o qual foram concebidas. As literaturas deixaram de ser nacionais para serem globais e de mercado.

Não obstante isso ser fato evidente e incancelável, uma (re) interpretação do processo formativo da literatura brasileira é importante para a compreensão não só da organização do Estado nacional e da cultura do país, mas também para o entendimento das condições históricas da produção e da composição das obras literárias. Nesse sentido, a retomada do debate sobre a história da literatura brasileira e o questionamento de seus marcos históricos são, cremos, necessários e oportunos para requalificar o exame crítico da literatura em particular e da cultura em geral, em um momento de desorientação de referências e paradigmas. 
Uma revisão crítica da formação e da realização plena da literatura brasileira, recolocando antigas controvérsias e problemas, aventa novas indagações e hipóteses. A proposta de redefinição das balizas históricas que intentamos delinear, sempre em interlocução com a obra seminal de Antonio Candido - que completa sessenta anos de sua publicação -, traz contribuição para o estudo da literatura produzida no decorrer do processo histórico do país.

\section{Referências}

BOSI, Alfredo. Introdução. In: BOSI, Alfredo (Org.). Araripe Júnior: teoria, crítica e história literária. Rio de Janeiro: Livros Técnicos e Científicos, 1978. p. IX-XX.

CAMPOS, Haroldo. O sequestro do barroco na formação da literatura brasileira. Salvador: Fundação Casa de Jorge Amado, 1989.

CANDIDO, Antonio. Formação da literatura brasileira: momentos decisivos. 4. ed. São Paulo: Martins, 1971. 2 v.

CANDIDO, Antonio. Literatura e cultura de 1900 a 1945. In: CANDIDO, Antonio. Literatura e sociedade: estudos de teoria e história literária. 5. ed. São Paulo: Nacional, 1976. p. 109-138. CANDIDO, Antonio. Iniciação à literatura brasileira. 4. ed. Rio de Janeiro: Ouro sobre Azul, 2004.

CARPEAUX, Otto Maria. História da literatura ocidental. São Paulo: Leya, 2011. v. 1.

CARVALHO, José Murilo de. Brasil: nações imaginadas. In: CARVALHO, José Murilo de. Pontos e bordados: escritos de história e política. Belo Horizonte: Ed. UFMG, 1999. p. 233268. 
COUTINHO, Afrânio. Introdução geral. In: COUTINHO, Afrânio (Org.). A literatura no Brasil. Rio de Janeiro: Sul Americana, 1955a. v. 1, p. 15-86.

COUTINHO, Afrânio. O regionalismo na prosa de ficção. In: COUTINHO, Afrânio (Org.). A literatura no Brasil. Rio de Janeiro: Sul Americana, 1955b. v. 2, p. 145-151.

COUTINHO, Afrânio. Conceito de literatura brasileira. Petrópolis: Vozes, 1981.

HANSEN, João Adolfo. Aleijadinho e outras representações: prefácio. In: GRAMMONT, Guiomar de. Aleijadinho e o aeroplano: o paraíso barroco e a construção do herói nacional. Rio de Janeiro: Civilização Brasileira, 2008. p. 17-31.

LEONEL, Maria Célia; SEGATTO, José Antonio. Formação da literatura e constituição do Estado nacional. In: LEONEL, Maria Célia; SEGATTO, José Antonio. Ficção e ensaio: literatura e história no Brasil. 1. reimpr. São Carlos: EdUFSCar, 2014. p. 165-186.

MOREIRA, Maria Eunice. Regionalismo literário rio-grandense: invenção da historiografia literária. In: MALLARD, Letícia et al. (Org.). História da literatura: ensaios. 2. ed. Campinas: Ed. da UNICAMP, 1995. p. 75-97.

MOREIRA, Maria Eunice. Apresentação. In: MOREIRA, Maria Eunice (Org.). Histórias da literatura: teorias, temas e autores. Porto Alegre: Mercado Aberto, 2003. p. 9-12.

NOVAIS, Fernando Antonio. Portugal e Brasil na crise do antigo sistema colonial: 1777-1808. 4. ed. São Paulo: Hucitec, 1986.

NUNES, Benedito. Historiografia literária. In: NUNES, Benedito. Crivo de papel. São Paulo: Ática, 1988. p. 205-246.

ROUANET, Maria Helena. Eternamente em berço esplêndido: a fundação de uma literatura nacional. São Paulo: Siciliano, 1991. 
SCHLEGEL, Karl Wilhelm Friedrich von. Introdução (à História da literatura europeia) - 1803-1804. In: SOUZA, Roberto Acízelo de (Org.). Uma ideia moderna de literatura: textos seminais para os estudos literários (1688-1922). Chapecó: Argos, 2011. p. 501-510.

SODRÉ, Nelson Werneck. História da literatura brasileira: seus fundamentos econômicos. 3. ed. Rio de Janeiro: J. Olympio, 1960.

VENTURA, Roberto. Estilo tropical: história cultural e polêmicas literárias no Brasil, 1870-1914. São Paulo: Companhia das Letras, 1991.

VENTURA, Roberto. História e crítica em Sílvio Romero. In:

MALLARD, Letícia et al. (Org.). História da literatura. 2. ed. Campinas: Ed. da UNICAMP, 1995. p. 37-54.

VERÍSSIMO, José. História da literatura brasileira: de Bento Teixeira (1601) a Machado de Assis (1908). 4. ed. Brasília: UNB, 1963. 